\title{
Effectiveness assessment of different methods of indium leaching from mobile phone screens
}

\author{
Anastasiia Chugainova ${ }^{1, *}$, and Larisa Rudakova ${ }^{1}$ \\ ${ }^{1}$ Perm National Research Polytechnic University, 614990, 29, Komsomolskii prospect, Perm, Russia
}

\begin{abstract}
The amount of electronic waste is growing annually all over the world, today it is almost 45 million tons. Less than $20 \%$ of electronic waste is being decontaminated and recycled. The rest is being taken to landfills or to places which are not supposed to store hazardous waste. This increases the adverse impact on the environment due to the fact that the waste consists of over $50 \%$ of hazardous components. At the same time, it also contains rare and expensive metals including indium. To extract indium from electronic waste it is necessary to justify the method of leaching. For this purpose research on leaching of indium from mobile phone screens has been done using various acids and parameters of the leaching process. As a result of the analysis, 6 methodologies were tested with various acid concentrations, the contact time of solid matter with a chemical reagent and temperature. The results of experimental research on the determination of metal concentration in mobile phone screens and the analysis of methods on indium leaching from mobile phone screens into a solution for further research are presented.
\end{abstract}

\section{Introduction}

To date, the literature data presents the classification of electronic waste, which is shown in fig. 1 [1, 2]. Methods for the disposal of electronic waste are also presented. However, these methods are mainly aimed at recycling the entire waste stream, which is not rational. This is regard to the fact that electronic waste is a resource potential of the rare and expensive metals. An international group of the researchers has proven the economic efficiency of the extraction of metals from electronic waste compared with the extraction of metals from the natural environment [3]. In this regard, it is necessary to search for the most effective and environmentally friendly methods for extracting the resource potential from electronic waste.

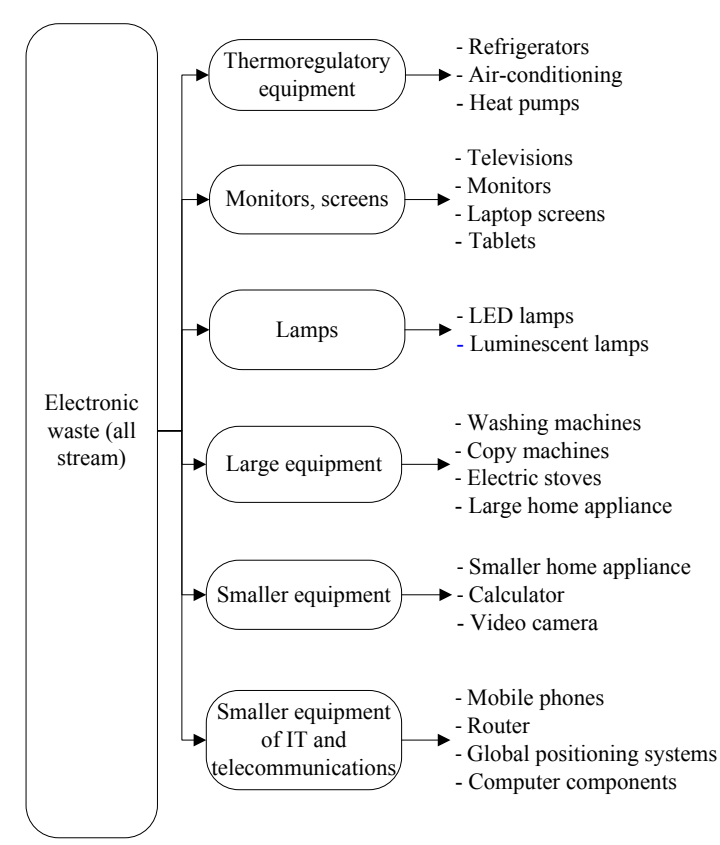

Fig. 1. Categories of electronic waste.

Electronic waste consists of 6 waste streams; each category of waste has an appropriate composition, durability, and impact on the environment and human health. In this regard, an individual approach is needed to solve the problem of neutralization and disposal of each waste stream.

In accordance with this, this study was aimed at a single stream of electronic waste, namely, mobile

\footnotetext{
* Corresponding author: chugainova a@mail.ru
} 
phones. To date, the average life of mobile phones in developed countries is no more than 2 years.

In the production of mobile phones, a significant amount of rare and expensive metals is used. The demand for mobile phones is increasing each year. In connection with this, the demand for rare and expensive metals such as indium, yttrium, neodymium, neodymium, and lanthanum is growing. The current trend creates the problems for their production. Since in the natural environment these metals are in small quantities, and significant costs are required for their extraction. These metals do not form independent deposits; they are in a dispersed state, which complicates their mining. The average content of rare metals in minerals is not more than $0.05-1 \%$. For this reason, an important step would be the creation of a cyclic rare metal circulation system. Rare and expensive metals are used not only in the manufacture of electronic devices, but also in the production of strategically important objects.

Mobile phones are a multi-component waste, as they consist of plastic, metal parts, hazardous and toxic components. Mobile phones include a significant amount of rare and expensive metals such as yttrium, indium, lanthanum, terbium, neodymium, gadolinium, praseodymium, gold, platinum and others. These metals are contained in various parts of mobile phones, therefore the process of their extraction and disposal is complicating. (Fig. 2).

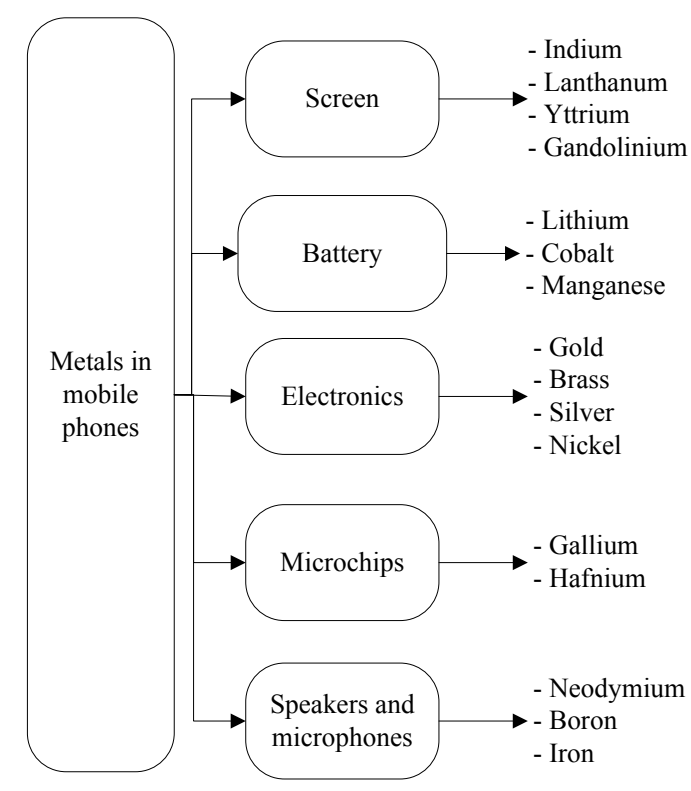

Fig. 2. Rare and expensive metals in mobile phones.

Unexplored components of mobile phones are screens that also contain rare and expensive metals. Screens are a mixture of plastic, metal base, various films, as well as an important component like a display, which contains rare and expensive components. To date, no studies have been conducted on the extraction of rare metals from the screens of mobile phones.

In this regard, the purpose of this study is to develop environmentally safe extraction of metals from the screens of mobile phones using the biotechnological method.

To achieve this goal it is necessary to solve the following tasks:

1. to analyze methods of leaching indium from the screens of mobile phones;

2. Select the most suitable leaching method for the efficient extraction of indium.

\section{Objects and methods of research}

The object of study is the crushed screens of mobile phones. The grinding was carried out using a ball mill company Retsch PM 100.

Qualitative and quantitative analysis of metals in the screens of mobile phones was carried out using an Inductively Coupled Plasma Optical Emission Spectrometer (ICP-OES) [4-9].

The next step in a study on the estimation of indium extraction from the screens of mobile phones by the biotechnological method is the leaching of indium into a solution. This solution will be further used for the biosorption process.

Before the start of experimental research, literature data was studied and the most suitable methods for leaching indium from the screens of mobile phones were selected [10].

Leaching of metals was carried out under various conditions using different acids, contact time, and temperature:

1. Concentrated sulfuric acid at the temperature $80^{\circ} \mathrm{C}$ for 72 hours. $5 \mathrm{ml}$ of acid and $10 \mathrm{ml}$ of distilled water were used for $15 \mathrm{~g}$ of sample $[11,12]$.

2. Concentrated hydrochloric acid at the temperature $80^{\circ} \mathrm{C}$ for 72 hours. $5 \mathrm{ml}$ of acid and $10 \mathrm{ml}$ of distilled water were used for $15 \mathrm{~g}$ of sample $[11,12]$.

3. Concentrated nitric acid at the temperature $80^{\circ} \mathrm{C}$ for 72 hours. $5 \mathrm{ml}$ of acid and $10 \mathrm{ml}$ of distilled water were used for $15 \mathrm{~g}$ of sample $[11,12]$.

4. Concentrated hydrochloric acid at the temperature $80^{\circ} \mathrm{C}$ for 5 hours. $5 \mathrm{ml}$ of acid and $10 \mathrm{ml}$ of distilled water were used for $15 \mathrm{~g}$ of sample $[11,12]$.

5. $1 \mathrm{M}$ solution of sulfuric acid in proportion with solid substance of the sample $50: 1(\mathrm{ml}: \mathrm{g})$ at the temperature $90^{\circ} \mathrm{C}$ for 1 hour [13].

6. Aqua regia in proportion 45:5:50 $\left(\mathrm{HCl}: \mathrm{HNO}_{3}: \mathrm{H}_{2} \mathrm{O}\right)$ at the temperature $60^{\circ} \mathrm{C}$ for 1 hour [14].

\section{Results and discussion}

The results of the qualitative and quantitative analysis of samples of the mobile phone screens for metal content are presented in the table 1 . 
Table 1. The results of qualitative and quantitative analysis of mobile phone screens.

\begin{tabular}{|c|c|}
\hline Metal & Concentration ranging g/kg \\
\hline Aluminum & $8.429-15.581$ \\
\hline Calcium & $4.649-7.064$ \\
\hline Boron & $4.060-6.579$ \\
\hline Magnesium & $2.740-6.176$ \\
\hline Strontium & $4.630-8.536$ \\
\hline \multicolumn{2}{|c|}{ Rare and expensive metals } \\
\hline Cerium & $0.102-0.135$ \\
\hline Erbium & $0.039-0.054$ \\
\hline Indium & $0.469-0.801$ \\
\hline
\end{tabular}

The concentrations of rare-earth metals in the screens of mobile phones are insignificant, which complicates their extraction. In this connection, indium was chosen for further research. Indium is also a rare and expensive metal and its concentration is enough for extraction from the mobile phone screens using biosorption.

Indium is a scattered metal without its own deposits, it can only be found in other ores, and the average content of indium in the ore is from $0.001 \%$ to $0.1 \%$. Indium belongs to hazard class III, the maximum permissible concentration (MPC) is $4 \mathrm{mg} / \mathrm{m}^{3}$ [15]. Indium metal is widely used in the manufacture of displays, solar panels, used in space technology, in the automotive industry for the production of engines, mirror coatings. Demand for this metal is increasing annually. Given the limited natural deposits of indium, the extraction of this metal from secondary sources is relevant.

The results of leaching indium from the screens of mobile phones using various methods are presented in table 2 .

Table 2. Results of leaching indium from mobile phone screens.

\begin{tabular}{|c|c|c|c|c|c|c|}
\hline \multirow{2}{*}{$\begin{array}{c}\text { Leaching methods } \\
\text { extraction }\end{array}$} & \multicolumn{7}{|c|}{} \\
\cline { 2 - 7 } & 1 & 2 & 3 & 4 & 5 & 6 \\
\hline In & 17.5 & 16.3 & 23.8 & 12.5 & 62.5 & 66.3 \\
\hline
\end{tabular}

The highest percentage of indium recovery of more than $60 \%$ is observed when using a $1 \mathrm{M}$ solution of sulfuric acid and another technique using aqua regia in a ratio of 45:5:50, the contact time is the same 1 hour.

The selection of the most suitable method for leaching indium from mobile phone screens was based not only on quantitative indicators, but also on economic factors. Upon receipt of the same working volume of the solution for further research, the use of aqua regia requires more than concentrated sulfuric acid. In connection with the rational use of resources and reducing the cost of initial reagents, it was decided to use the method of leaching indium from the screens of mobile phones using a $1 \mathrm{M}$ solution of sulfuric acid.

\section{Conclusion}

The analysis of the component composition of the screens of mobile phones proved that the composition of the displays contains rare and expensive metals. These metals are in sufficient quantities for their extraction and further use in the production cycle. The indium concentration in the screens of mobile phones was $0.8 \mathrm{~g} / \mathrm{kg}$.

The best method for leaching indium from the screens of mobile phones, namely $1 \mathrm{M}$ sulfuric acid solution, at an exposure temperature of $90{ }^{\circ} \mathrm{C}$ for 1 hour, the ratio of solid to $1 \mathrm{M}$ solution was 1:50 was chosen experimentally. The resulting concentration of indium as a result of leaching is sufficient for the biosorption process. The concentration of indium in solution after leaching with this technique was $0.5 \mathrm{~g} / \mathrm{kg}$, which corresponds to an extraction efficiency of more than $60 \%$.

\section{References}

[1] C.P. Baldé, V. Forti, V. Gray, R. Kuehr, P. Stegmann, The Global E-waste Monitor - 2017, United Nations University (UNU), International Telecommunication Union (ITU) \& International Solid Waste Association (ISWA), Bonn, Geneva, Vienna (2017).

[2] Directive WEEE 2012/19/EU the Waste Electrical and Electronic Equipment Directive.

[3] X. Zeng, J.A. Mathews, J. Li, Environmental Science \& Technology, Publication Date (Web) (4 April 2018).

[4] DIN EN 16174, Schlamm, behandelter Bioabfall und Boden - Aufschluss von mit Königswasser löslichen Anteilen von Elementen; Deutsche Fassung EN, 16174 (2012).

[5] B.V. Elsevier, Microwave-Assisted Sample Preparation for Trace Element Determination, 416 (2014).

[6] Cezar A. Bizzi, Erico M.M. Flores, Juliano S. Barin, Edivaldo E. Garcia, Joaquim A. Nóbrega, Microchemical Journal, 99, 193-196 (2011).

[7] Wen-Si Zhong, Ting Ren, Li-Jiao Zhao, Journal of food and drug analysis, 24, 46-55 (2016).

[8] Fahad N. Assubaie, Arabian Journal of Chemistry, 8, 240-245 (2015).

[9] Fernanda C. Bressy, Geysa B. Brito, Isa S. Barbosa, Leonardo S.G. Teixeira, Maria Graças A. Korn, Microchemical Journal, 109, 145-149 (2013).

[10] A.B. Argenta, C.M. Reis, G.P. Mello, G.L. Dotto, E.H. Tanabe, D.A. Bertuol, J. of Supercritical Fluids, 120, 95-101 (2017).

[11] Mehmet Ali Kucuker, Nils Wieczorek, Kerstin Kuchta, Nadim K. Copty, PLoS ONE, 12, 4 (2017).

[12] Mehmet Ali Kücüker, Jean-Baptiste Nadal, Kerstin Kuchta, International journal of plant, animal and environmental sciences, 203, 197 (2016).

[13] A.V.M. Silveira, M.S. Fuchs, D.K. Pinheiro, E.H. Tanabe, D.A. Bertuol, Waste Management, 45, 334-342 (2015). 
[14] Jinhui Li, Song Gao, Huabo Duan, Lili Liu, Waste Management, 29, 2033-2039 (2009).

[15] Decree of the Chief State Sanitary Doctor of the Russian Federation of 13 February 2018, no. 25 , "On the approval of hygienic standards 2.2.5.3532-18", Maximum permissible concentrations (MPC) of harmful substances in the air of the working area. 